\title{
Negative-Ion Formation in the Explosives RDX, PETN, and TNT By Using the Reversal Electron Attachment Detection Technique
}

\author{
S. Boumsellek, S. H. Alajajian, and A. Chutjian \\ Jet Propulsion Laboratory, California Institute of Technology, Pasadena, California, USA
}

\begin{abstract}
First results of a beam-beam, single-collision study of negative-ion mass spectra produced by attachment of zero-energy electrons to the molecules of the explosives RDX, PETN, and TNT are presented. The technique used is reversal electron attachment detection (READ) wherein the zero-energy electrons are produced by focusing an intense electron beam into a shaped electrostatic field which reverses the trajectory of electrons. The target beam is introduced at the reversal point, and attachment occurs because the electrons have essentially zero longitudinal and radial velocity. The READ technique is used to obtain the "signature" of molecular ion formation and/or fragmentation for each explosive. Present data are compared with results from atmospheric-pressure ionization and negative-ion chemical ionization methods. (J Am Soc Mass Spectrom 1992, 3, 243-247)
\end{abstract}

$\mathrm{I}$

n the search for high sensitivity and direct atmospheric sampling of trace species, techniques have been developed such as atmospheric-sampling glow-discharge ionization (ASGDI) [1, 2], atmospheric pressure ionization (API) [3], electron-capture detection (ECD) $[4,5]$, and negative-ion chemical ionization (NICI) [6] that are capable of detecting partsper-billion to parts-per-trillion concentrations of trace species, including explosives, in ambient air. These techniques are based on positive- or negative-ion formation via charge transfer to the target, or electron capture under multiple-collision conditions in a Maxwellian distribution of electron energies at the source temperature. Subsequent detection of the ionmolecule reaction products or the electron-attachment products is carried out by using time-of-flight, quadrupole, magnetic-sector, ion trap or analog current measurement methods.

One drawback of the high-pressure, corona- or glow-discharge devices is that they are susceptible to interferences either through indistinguishable product masses, or through undesired ion-molecule reactions. The ASGDI technique is relatively immune from such interferences, since at target concentrations of $<1$ ppm the majority of negative ions arises via electron capture rather than through ion-molecule chemistry [2]. A drawback of the conventional ECD, and possibly of the ASGDI, is that they exhibit vanishingly small densities of electrons with energies in the range

Address reprint requests to Ara Chutjian, Jet Propulsion Laboratory, California Institute of Technology, 4800 Oak Grove Drive, Pasadena, CA 91109.
0-10 meV, as can be seen from a typical Maxwellian electron energy distribution function at $T=300 \mathrm{~K}$. Slowing the electrons to these subthermal ( $<10 \mathrm{meV}$ ) energies is crucial because the cross section for attachment of several large classes of molecules-including the explosives, chlorohalocarbon compounds and perfluorinated carbon compounds-is known to increase to values larger than $10^{-12} \mathrm{~cm}^{2}$ at near-zero electron energies [7-9]. In fact, in the limit of zero energy these cross sections are predicted to diverge as $\epsilon^{-1 / 2}$, where $\epsilon$ is the electron energy. This is a direct consequence of the Wigner threshold law for electron at tachment $[7,10]$.

To provide a better "match"' between the electron energy distribution function and attachment cross section, a new concept of attachment in an electrostatic mirror was developed [11]. In this scheme, electrons are brought to a momentary halt by reversing their direction with electrostatic fields. At this turning point the electrons have zero or near-zero energy. A beam of target molecules is introduced, and the resultant negative ions are extracted. This basic idea has been recently improved to allow for better reversal geometry, higher electron currents, lower backgrounds, and increased negative-ion extraction efficiency $[12,13]$. We present herein application of the so-called reversal electron attachment detector (READ) to the study of negative-ion formation in the explosives RDX, PETN, and TNT under single-collision conditions. The technique exploits the fact that these molecules are known, indirectly through results in the ECD [5], to attach thermal-energy electrons. Present results provide the first direct experimental verification that the explo- 
sives molecules attach zero-energy electrons, and offer the dissociative attachment fragmentation pattern for each target.

The READ technique is a new analytical tool which differs in several significant ways from other methods. Because READ builds up electron density in the energy region of maximum attachment cross section, attachment (ionization) efficiencies are expected to be high. Indeed, the sensitivity of the READ to the detection of $\mathrm{Cl}^{-}$ions from $\mathrm{CCl}_{4}$ has been measured to be 10 pptr with a counting rate of $900 \mathrm{~Hz}$ [13]. Neither attachment cross sections nor rate constants for the explosives are available. Assuming values comparable to $\mathrm{CCl}_{4}$, this would give a sensitivity of READ, in the design used herein, of pptr $(90 \mathrm{~Hz})$ to explosives.

Unlike the ASGDI, API, ECD, or NICI techniques, negative-ion generation by reversal electron attachment is also able to access resonance at $\epsilon>0$, beyond the range of thermalized energies. This is accomplished by shifting the location of the electron turning point with respect to the target beam [12]. Furthermore, because measurements are carried out under single-collision conditions, there is no ion-molecule chemistry to speak of. Finally, since one is detecting product masses, the READ method is capable of identifying one or more "signature" ions in the attachment process. In applications where time is not critical, one can envisage the use of several mass detectors to detect products in coincidence. This would mitigate strongly against interferences, and could even identify directly which type(s) of explosives were being detected. However, a sobering problem awaiting "in the wings" with the READ, and with any single-collisions technique, is that of sample introduction from atmosphere to vacuum. This work is currently underway in our laboratory.

\section{Experimental Methods}

\section{Instrument Description}

A schematic diagram of the READ apparatus is shown in Figure 1, and details of its operation have been given elsewhere $[12,13]$. READ consists of an indirectly-heated cathode $F$ from which electrons are extracted, accelerated by a five-element lens system, and focused into an electrostatic mirror. The mirror decelerates the electron beam to zero longitudinal and radial velocity at the reversal plane $R$ (Figure 1). The electron beam is square-wave modulated by fast switches $S_{1}-S_{3}$ with a nearly $50 \%$ duty cycle. These switches are power MOSFET-based to ensure fast (50 ns) rise times between full-floating lens voltage [14].

Electron attachment to the explosives target takes place at $R$ during one half of the pulse cycle. The resulting negative ions are extracted during the second half (electron beam pulsed off), then focused, deflected by a $90^{\circ}$ electrostatic analyzer (ESA) to en-

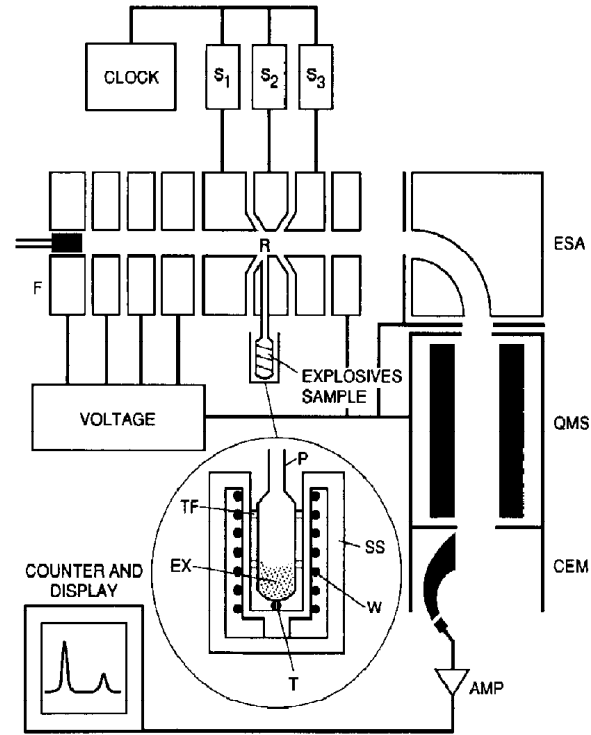

Figure 1. Schematic diagram of the READ apparatus, with detail of the explosives sample tube. Electrons are generated at the filament $F$, accelerated into the reversal region $R$ where attachment takes place. Fast switches $S_{1}-S_{3}$ pulse electrons on during one-half cycle, then pulse negative ions out towards the electrostatic analyzer (ESA) during the second half. Ions are focused into the quadrupole mass spectrometer (QMS), detected at the channel electron multiplier (CEM), amplifed, and counted. Detail shows the heated tube (P), sample (EX), heater wires (W), thermocouple (T), teflon spacer (TF), and stainless steel outer heat shield (SS).

sure the sign of charge, and further focused onto the entrance plane of a quadrupole mass analyzer (QMS). Ion counts are recorded in a multichannel scaling mode using an Ortec 7100 (Oak Ridge, TN) multichannel analyzer interfaced to an Extrel (Pittsburgh, PA) quadrupole mass controller. Spectra are obtained by scanning the masses transmitted by the quadrupole and are recorded in 1024 channels with a dwell time of 0.15 per channel.

\section{Explosives Handling}

Because of the low vapor pressure of the explosives targets, and their tendency to adsorb to most surfaces, special care had to be taken to transport the target into the reversal region; and to ensure that there was no contamination among the RDX, PETN, and TNT measurements. Each solid target was placed in a pyrex bulb $P$ (Figure 1) inside the vacuum chamber. The vapor pressures at $300 \mathrm{~K}$ of RDX, PETN, and TNT are quite low: $8.5 \times 10^{-7}, 2.7 \times 10^{-6}$, and $1.3 \times$ $10^{-3} \mathrm{~Pa}$, respectively [15]. Hence, the bulb had to be heated, with nichrome wire wound around the out- 
side body. The resulting vapor was conducted to $R$ through a heated stainless-steel tube. Typical required temperatures, as read with a copper-constantan thermocouple $T$, were $343 \mathrm{~K}$ for TNT, and $378 \mathrm{~K}$ for RDX and PETN. Operating pressures in the vacuum chamber were $(5.3-13) \times 10^{-5} \mathrm{~Pa}$, with a base pressure of $1 \times 10^{-5} \mathrm{~Pa}$.

Between sample measurements, it was essential to clean the apparatus and all connecting tubing to avoid any intercontamination ("memory") effects. After each sample, the lens system was disassembled, the electrodes were thoroughly cleaned in acetone, and the apparatus was baked to $415 \mathrm{~K}$ using a quartz-iodine lamp placed near the collision region, with no sample bulb in place. Spectra were recorded on this blank run to measure the background in the mass range $m / e=$ 20-300. The background was found to be flat, except for a persistent, weak feature at $m / e=43$ which also contributed weakly to the explosives spectra. After this blank run, the vacuum chamber was opened, the next target was introduced in its separate pyrex bulb and connecting tube, and measurements were initiated. In practice, it was found that baking had the major cleaning effect for the explosives. Thus in an actual working instrument one would maintain the optics and connecting tubing at an elevated temperature and could, after each sample, "flash" heat the collision region.

Explosives samples were supplied by the Department of Transportation, and were from Eastman Kodak (TNT), and Ensign Bickford (RDX and PETN). The Ensign Bickford samples were stated as $98.5 \%$ pure, and stabilized in a $1 \%$ wax and $0.5 \%$ graphite mixture. In that neither hydrocarbons (wax) nor carbon (graphite) attach thermal-energy electrons, no difficulty due to these impurities was anticipated. To check this a separate, $100 \%$ pure PETN sample was taken from a length of detonation cord. This gave identical spectra to the Ensign Bickford stabilized PETN.

\section{Results and Discussion}

Negative-ion mass spectra of RDX, PETN, and TNT are presented in Figures 2-4, respectively. Several spectra, taken on different days, were recorded for each molecule. For each spectrum, a recording time 0.5-2 $\mathrm{h}$ was needed to scan 200-300 u with a resultant signal/background of 50-150. Spectra were obtained with a mass resolution of $\Delta m=0.9$ (FWHM), using low extraction voltages in the ion lens system and low acceleration voltages in the quadrupole rods $(0-10 \mathrm{~V})$. To (1) focus the incident electron beam at the reversal plane, (2) check the calibration of the mass scale, and (3) monitor the spectral lineshapes, one first observed the zero-energy electron attachment products in $\mathrm{CCl}_{4}, \mathrm{c}-\mathrm{C}_{6} \mathrm{~F}_{6}$, and $\mathrm{c}-\mathrm{C}_{5} \mathrm{~F}_{8}$. Electron attachment in $\mathrm{CCl}_{4}$ leads via dissociative attachment to form solely the isotopes ${ }^{35} \mathrm{Cl}^{-}$and ${ }^{37} \mathrm{Cl}^{-}[8]$. The

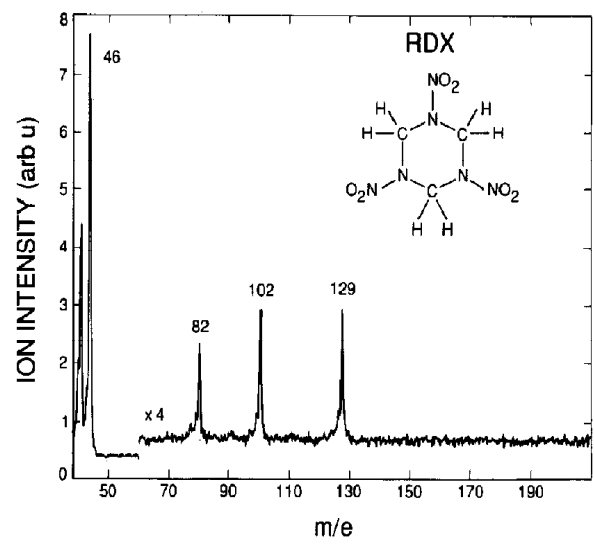

Figure 2. Negative-ion mass spectrum of RDX formed in zeroenergy electron attachment.

targets $c-\mathrm{C}_{6} \mathrm{~F}_{6}$ and $\mathrm{c}-\mathrm{C}_{5} \mathrm{~F}_{8}$ form only the molecular ions $\mathrm{c}^{-} \mathrm{C}_{6} \mathrm{~F}_{6}^{-}$and $\mathrm{c}_{-} \mathrm{C}_{5} \mathrm{~F}_{8}^{-}$at $m / e=186$ and 212 , respectively. These ions served to calibrate the entire range of the mass scale. No correction between the nominal and true mass reading was required. All lineshapes were single symmetrical peaks with no detectable "rod splittings."

The fragmentation pattern ("signature") of each explosives molecule was recorded between mass 30 and the mass corresponding to the molecular ion. Spectra are not reported below mass 40 . This region, during blank runs, contained the two peaks at $m / e=$ 35 and 37 due to persistent $\mathrm{CCl}_{4}$ adsorbed on the optics surfaces. In addition, there was a strong, continuous background, starting at $m / e=20$ and extending towards $m / e=1$, which was assumed to arise from scattered and extracted electrons from the gun.

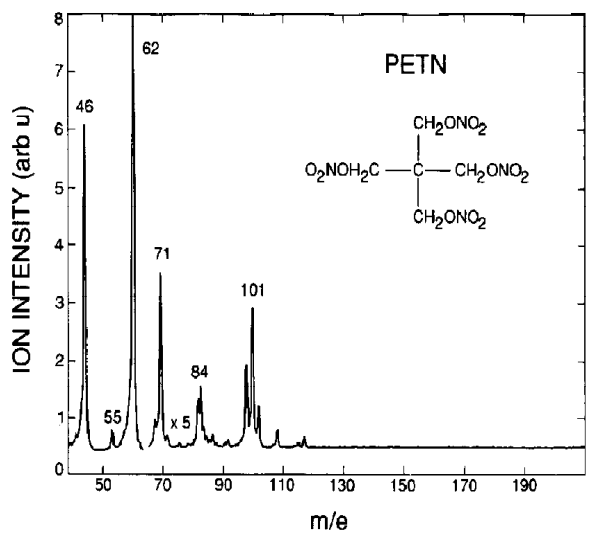

Figure 3. Negative-ion mass spectrum of PETN formed in zero-energy electron attachment. 


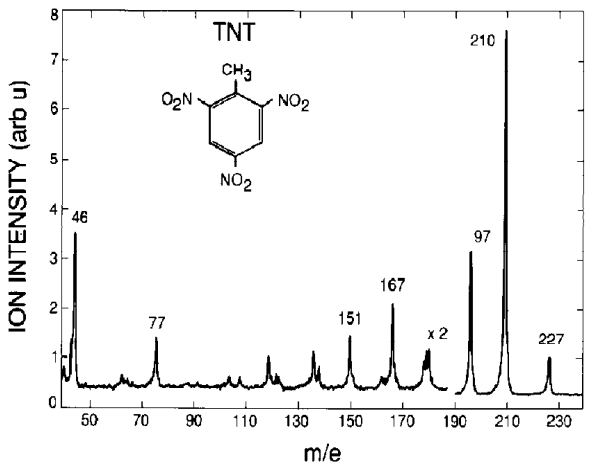

Figure 4. Negative-ion mass spectrum of TNT formed in zeroenergy electron attachment.

Each of the three explosives spectra shows an abundance of the $\mathrm{NO}_{2}^{-}$ion at $m / e=46$. This is in agreement with methods using a multiple-collision, high source-pressure (NICI) environment [16]. It is useful to point out that, unlike in NICI $[16,17]$, no masses greater than the parent ion mass can be observed in this work, since one is in a single-collision regime, with crossed (or just touching!) beams of electrons and target. In the following, differences among the three spectra will be noted, with attention given to the mass peaks that are characteristic of each explosive. Counting rates for the strongest peaks were in the range $700-1200 \mathrm{~Hz}$.

\section{RDX}

The base (most intense) peak in RDX is at $m / e=46$ $\left(\mathrm{NO}_{2}^{-}\right)$. Three additional strong peaks are found at $m / e=82,102$, and 129 . The mass 82 may correspond to the loss of $\mathrm{NO}_{2} \mathrm{HNO}_{2} \mathrm{HNO}_{2}$, and that at 129 to loss of $\mathrm{NO}_{2} \mathrm{HNO}_{2}$. The mass 102 peak may be attributed to the $\mathrm{CH}_{2} \mathrm{NCH}_{2} \mathrm{NNO}_{2}^{-}$fragment ion. Mass locations and assignments are listed in Table 1.

The above peaks have been observed in NICI [17, 18], but with different relative intensities. No molecular ion peak nor adjacent peaks were observed in the present work, while peaks in NICI were observed at $m / e=221\left[(\mathrm{RDX}-\mathrm{H})^{-}\right]$and $223\left[(\mathrm{RDX}+\mathrm{H})^{-}\right]$at a 11-53 Pa source pressure [17]. A strong peak at $m / e$ $=176\left[\left(\mathrm{RDX}^{-\mathrm{NO}_{2}}\right)^{-}\right]$was not observed, but has been

Table 1. Mass numbers and identification of features in the zero-energy attachment spectrum of RDX

\begin{aligned} & \hline Mass \multicolumn{1}{c}{ Identification } \\ & \hline \hline 129$\left(\mathrm{RDX}-\mathrm{NO}_{2} \mathrm{HNO}_{2}\right)^{-} \\ & 102\left(\mathrm{CH}_{2} \mathrm{NCH}_{2} \mathrm{NNO}_{2}\right)^{-} \\ & 93 \mathrm{NO}_{2} \mathrm{HNO}_{2}^{-} \\ & 82\left(\mathrm{RDX}_{2}-\mathrm{NO}_{2} \mathrm{HNO}_{2} \mathrm{HNO}_{2}\right)^{-} \\ & 46 \mathrm{NO}_{2}^{-} \\ &$\hline\end{aligned}

noted by others $[2,17,18]$ at higher pressures. Such differences are very likely due to collisional stabilization, with respect to autoionization, of the mass 176 ion, under the high-pressure (multiple-collision) conditions of the NICI and API sources.

\section{PETN}

Two peaks at $m / e=46\left(\mathrm{NO}_{2}^{-}\right)$and 62 dominate the spectrum, consistent with the NICI spectrum [17]. The base peak at 62 is attributed to the formation of $\mathrm{NO}_{3}^{-}$.

Relatively weak features at $m / e=84$ and 101 could be due to $\left(\mathrm{C}_{2} \mathrm{H}_{2} \mathrm{~N}_{3} \mathrm{O}\right)^{-}$and (PETN$\left.2 \mathrm{CH}_{2} \mathrm{ONO}_{2} \mathrm{HNO}_{3}\right)^{-}$ions, respectively. However, no assignments could be suggested for the features at $m / e=55,71$ and the small peak $m / e=120$. Mass locations and assignments are listed in Table 2.

\section{TNT}

The READ spectrum of TNT is rich in features. The mass locations and assignments are given in Table 3. The fragment $m / e=210\left[(\mathrm{TNT}-\mathrm{OH})^{-}\right]$dominates the spectrum, but intense peaks also appear at $m / e=197$ [(TNT-NO $\left.)^{-}\right]$and $46\left[\left(\mathrm{NO}_{2}\right)^{-}\right]$. Molecular ions $(\mathrm{m} / \mathrm{e}$ $=227$ ) are also produced efficiently, but are more abundant in the NICI [17, 18] and API [2] sources. While most peaks in the present spectrum are consistent with those in refs 2,17 , and 18 the relative intensity is different in all three sources. From other low-energy electron attachment results [19], one can assume that the relative intensities of the peaks will depend on electron energy (for READ or other lowenergy, single-collision experiments), electron energy distribution function (for API), as well as on the total source pressure (for NICI and API) leading to stabilization. The molecular ion and $\mathrm{NO}_{2}^{-}$have also been detected in electron-swarm measurements in nitrobenzene, o-nitrotoluene, and $m$-nitrotoluene [20], molecules sometimes studied as TNT simulants.

\section{Conclusions}

The present results provide the first spectra for electron attachment to RDX, PETN, and TNT at zero

Table 2. Mass numbers and identification of features in the zero-energy attachment spectrum of PETN

\begin{tabular}{rl}
\hline Mass & \multicolumn{1}{c}{ Identification } \\
\hline 109 & {$\left[\mathrm{OH}\left(\mathrm{NO}_{2}\right)_{2}\right]^{-}$} \\
703 & $?$ \\
101 & $\left(\mathrm{PETN}_{2}-\mathrm{CH}_{2} \mathrm{ONO}_{2} \mathrm{HNO}_{3}\right\}^{-}$ \\
99 & $?$ \\
84 & $\left(\mathrm{C}_{2} \mathrm{H}_{2} \mathrm{~N}_{3} \mathrm{O}\right)^{-}$ \\
71 & $?$ \\
62 & $\mathrm{NO}_{3}^{-}$ \\
55 & $?$ \\
46 & $\mathrm{NO}_{2}^{-}$ \\
\hline
\end{tabular}


Table 3. Mass numbers and identification of features in the zero-energy attachment spectrum of TNT

\begin{tabular}{|c|c|}
\hline Mass & Identification \\
\hline 227 & (TNT) $)^{-}$ \\
\hline 210 & (TNT-OH) $^{-}$ \\
\hline 197 & $(T N T \cdot N O)^{-}$ \\
\hline 181 & $\left(\mathrm{TNT}-\mathrm{NO}_{2}\right)^{-}$ \\
\hline 167 & (TNT-2NO) ${ }^{-}$ \\
\hline 151 & $\left(\mathrm{TNT}_{-} \mathrm{NO}_{2}-\mathrm{NO}\right)^{-}$ \\
\hline 139 & $?$ \\
\hline 137 & (TNT-3NO) ${ }^{-}$ \\
\hline 120 & $\left(\mathrm{TNT}-2 \mathrm{NO}-\mathrm{HNO}_{2}\right)^{-}$ \\
\hline 109 & 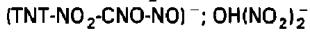 \\
\hline 105 & $\left(\mathrm{TNT}-2 \mathrm{NO}_{2}-\mathrm{NO}\right)^{-}$ \\
\hline 77 & $\left\{\mathrm{TNT}-\mathrm{NO}_{3}-\mathrm{NO}_{2}-\mathrm{CNO}\right\}^{-}$ \\
\hline 46 & $\mathrm{NO}_{2}^{-}$ \\
\hline
\end{tabular}

electron energy, and under single-collision conditions. They confirm the fact that the conventional ECD operates by setting up an electron energy distribution function with maximum at a relatively low electron energy (e.g., $0.039 \mathrm{eV}$ at $300 \mathrm{~K}$ ), which overlaps a portion of the attachment cross section of the explosives. The READ technique, on the other hand, concentrates the electron energy distribution at much lower energies, into the energy region of the divergent (s-wave) maximum of the electron attachment cross section in each molecule.

Furthermore, a signature has been obtained in each of the explosives. Indeed, four peaks at $m / e=46,82$, 102, and 129 are characteristic of RDX; two peaks at 46 and 62 are characteristic of PETN; and three peaks at 46,197 , and 210 are characteristic of TNT. In an actual working detector, a strategy of "prescreening" could be realized with a detector tuned at the common peak $m / e=46$, followed by an additional measurement at $m / e=129$ (for RDX), 62 (for PETN), and 210 (for TNT), if such information is desired.

Efforts are currently underway to increase the sensitivity of the present READ device. Portions of the lens system have been redesigned to transport a greater electron current into a larger collision volume. Space-charge limited calculations using a spherical cathode indicate, conservatively, a factor of 20 increase in electron current reversed in the collision region. This, combined with a factor of 3 increase in attachment volume, should yield an improvement of a factor of 60 in sensitivity, Methods are also being explored for introducing samples from atmospheric pressure into vacuum. In parallel, a second apparatus is being assembled to probe the shape of the electron-attachment profiles of the explosives. It is based on the technique, used in this laboratory, of photoionization of a rare gas to produce low-energy electrons at high energy resolution (see ref 8 , and references therein). In its new version, ionization would be carried out through laser-produced UV radiation to attain higher resolution, lower energies, and greater sensitivity.

\section{Acknowledgments}

We thank Dr. J. Hobbs for samples of the explosives. This work was carried out at the Jet Propulsion Laboratory, California Institute of Technology, and was supported by the Department of Transportation through agreement with the National Aeronautics and Space Administration.

\section{References}

1. McLuckey, S. A.; Glish, G. L.; Asano, K. G.; Grant, B. C. Anal. Chem. 1988, 60, 2220-2227. McLuckey, S. A.; Glish, G. L.; Asano, K. G. Anal. Chim. Acta 1989, 225, 25-35.

2. McLuckey, S. A.; Glish, G. L.; Grant, B. C. In Proc. 3rd Symp, Anal. Det. Explosizes, Mannheim, Germany, July 1989.

3. Huang, E. C.; Wachs, T.; Conboy, J. J.; Henion, J. D. Anal. Chem. 1990, 62, 713-725.

4. Lovelock, J. E. In Applied Atomic Collision Physics; H. S. W. Massey; E. W. McDanjel; B. Bederson, Eds.; Academic: New York, 1982; Vol. 5, p 1.

5. Conrad, F. J.; Peterson, P. K. In Proceedings of New Concepts Symposium and Workshop on Detection and Identification of Explosties, NTIS Publ. PB-296 055: Reston, VA, 1978; P 277.

6. Daugherty, R. C. Anal. Chem. 1981, 53, 625A-636A.

7. Orient, O. J.; Chutjian, A.; Crompton, R. W.; Cheung, B. Phys. Rev. A 1989, 39, 4494-4501,

8. Chutjian, A.; Alajajian, S. H. Phys. Rev. A 1985, 31, 2885-2892.

9. Chutjian, A.; Alajajian, S. H. J. Phys. B 1985, 18, 4159-4167.

10. Wigner, E. P. Phys. Rev. 1948, 73, 1002-1009.

11. Otient, O. J.; Chutjian, A.; Alajajian, S. H. Rev. Sci. Instrum. 1985, 56, 69-72.

12. Bernius, M. T.; Chutjian, A. J. Appl. Phys. 1989, 66, 2783-2788.

13. Bernius, M. T.; Chutjian, A. Anal. Chem, 1990, 62, 1345-1349.

14. Bernius, M. T.; Chutjian, A. Reo. Sci. Instr. 1990, 61, 925-927. Bernius, M. T,; Chutjian, A. Reo. Sci. Instrum $1989,60,779-782$.

15. Dionne, B. C.; Rounbehler, D. P.; Achter, E. K.; Hobbs, J. R.; Fine, D. H. J. Energ. Mater. 1986, 4, 447-472.

16. Yinon, J. Mass Spectrom. Rev. 1982, 1, 257-307.

17. Yinon, J. J. Forensic Sci. 1980, 25, 401-407.

18. McLuckey, S. A.; Glish, G. L.; Kelley, P. E. Anal. Chem. 1987, 59, 1670-1674.

19. Yinon, J.: Boettger, H. G.; Weber, W. P. Anal. Chem. 1972, 44, 2235-2237.

20. Christophorou, L. G.; Compton, R. N.; Hurst, G. S; Reinhardt, P. W. J. Chem. Phys. 1966, 45, 536-547. 